\title{
Imaging of otosclerosis
}

\section{Bildgebung der Otosklerose}

Authors

Sabrina Kösling1', Stefan K Plontke², Sylva Bartel²

\author{
Affiliations \\ 1 Department of Radiology, Martin-Luther-University \\ Halle-Wittenberg, Halle, Germany \\ 2 ENT Department, Martin-Luther-University \\ Halle-Wittenberg, Halle, Germany
}

Key words

otosclerosis, stapedoplasty, MRI, CB-CT, CT

received 20.01.2020

accepted 07.02.2020

Bibliography

DOI https://doi.org/10.1055/a-1131-7980

Published online: 26.3.2020

Fortschr Röntgenstr 2020; 192: 745-753

(c) Georg Thieme Verlag KG, Stuttgart · New York

ISSN 1438-9029

Correspondence

Prof. Sabrina Kösling

Universitätsklinik und Poliklinik für Radiologie, Martin-LutherUniversität, Ernst-Grube-Str. 40, 06097 Halle, Germany

Tel.: ++49/3 45/5574141

Fax: ++49/3 45/5 572157

sabrina.koesling@medizin.uni-halle.de

\section{ABSTRACT}

Background Otosclerosis is an important cause of hearing loss and a widespread pathology in ENT medicine. Although a high diagnostic value of $\mathrm{CT}$ with impact on therapy is emphasized in the literature, the disease is seldom seen in the radiological routine diagnostics due to ENT findings often being diagnostic. Radiologists detect it rather more often in cases of unclear hearing loss or cochlear implant candidates. The findings may be very subtle. They require a target search and an optimal imaging technique.

Methods This review article is based on a selective search of the literature in PubMed without any time frame restrictions as well as on the long clinical experience of the authors.

Results The paper focuses on imaging aspects of otosclerosis: current role, advice for imaging technique, characteristic imaging signs, radiological differential diagnoses and findings after stapedoplasty. Pathology, clinical signs and therapeutic options are summarized briefly.

Conclusions With an optimal technique and sufficient radiological experience otosclerosis can be correctly diagnosed by imaging in a high percentage of cases. Radiology plays the key role in the diagnosis of retrofenestral otosclerosis. It can provide valuable information for the management of complications after stapedotomy.

\section{Key points:}

- X-ray cross-sectional imaging continues to be the method of first choice in the radiological diagnostics of otosclerosis

- With an optimal imaging technique and sufficient experience otosclerosis can be radiologically detected

- In complications after stapedoplasty, causes can be identified supporting the indication for a reoperation

\section{Citation Format}

- Kösling K, Plontke SK, Bartel S. Imaging of otosclerosis. Fortschr Röntgenstr 2020; 192: 745-753

\section{ZUSAMMENFASSUNG}

Hintergrund Die Otosklerose ist eine wichtige Ursache für Schwerhörigkeit und gilt in der HNO-Heilkunde als verbreitetes Krankheitsbild. Obwohl in der Literatur die hohe diagnostische Wertigkeit der CT mit Einfluss auf das therapeutische Vorgehen hervorgehoben wird, zählt die Erkrankung in der radiologischen Routinediagnostik aufgrund oft diagnoseweisender klinischer Befunde zu den seltenen Indikationen. Radiologisch wird sie häufiger bei unklarer Schwerhörigkeit oder in der präoperativen Cochlea-Implantat-Diagnostik entdeckt. Die Befunde können sehr subtil sein, bedürfen einer gezielten Suche und optimalen Untersuchungstechnik.

Methode Diese Übersichtsarbeit beruht auf einer selektiven Literaturreche in PubMed ohne Zeitraumbegrenzung und der langjährigen klinischen Erfahrung der Autoren.

Ergebnisse Dieser Beitrag hat die Otosklerose unter verschiedenen Gesichtspunkten zum Inhalt: Pathologie, klinische Zeichen und Therapieoptionen werden überblickmäßig dargestellt; das Hauptaugenmerk liegt auf der Bildgebung mit heutigem Stellenwert, untersuchungstechnischen Hinweisen, charakteristischen Bildbefunden, radiologischen Differenzialdiagnosen und bildgebenden Befunden nach Stapesplastik. Schlussfolgerung Bei optimaler Untersuchungstechnik und ausreichender Erfahrung kann die Otosklerose in einem hohen Prozentsatz radiologisch diagnostiziert werden. Eine diagnoseentscheidende Rolle hat der Radiologe bei der retrofenestralen Form der Otosklerose. Im postoperativen Komplikationsmanagement kann er dem HNO-Arzt wertvolle Informationen liefern. 


\section{Introduction}

Otosclerosis is the most common osteodystrophy of the temporal bone, and only this disease exclusively affects the petrous bone. It is a significant cause of hearing loss. The histological prevalence is about $2.5 \%$ (up to $10 \%$ ), clinically it is significantly lower at $0.3 \%$ $0.4 \%$ in Caucasians and only $0.03 \%-0.1 \%$ in the African and Asian populations [1]. The disease usually manifests itself in the $3^{\text {rd }}-4^{\text {th }}$ decade of life and occurs bilaterally in $70 \%-85 \%$ of cases [1], and appears rarely in children [2]. Tending to run in families, twice as many females are affected compared to males [1].

Although otosclerosis is a common disease in ENT medicine, it is rarely encountered by radiologists, most frequently in clarification of unexplained hearing loss or in preoperative cochlear implant $(\mathrm{Cl})$ diagnostics or postoperatively in the event of complications. Less frequently there is a specific request for evidence of otosclerosis. X-ray cross-sectional imaging is the method of choice for the detection of otosclerotic foci. The findings can be very subtle and require a targeted search and as well as an optimal examination technique.

This article is intended to inform the reader about otosclerosis with main focus on the current status of imaging, image morphological signs and imaging findings after stapedoplasty.

\section{Etiology and Histopathogenesis}

The etiology of otosclerosis is largely not understood. The following models are discussed: Genetic causes (most likely autosomal dominant inheritance), autoimmunity, cytokines of bone metabolism, measles infection, hormones, environmental influences $[3,4]$.

Histological examinations have demonstrated that otosclerosis is characterized by focal changes in the bony labyrinth that occur in stages. Four stages have been distinguished:

- Stage I: Inflammatory resorption of woven bone of the otic capsule by osteoclasts.

- Stage II: Replacement by spongy vascular bone (otospongiotic phase).

- Stage III: Osteoclastic degradation of the spongy bone, replacement by compact lamellar bone (otosclerotic phase).

- Stage IV: Suspension of remodeling processes, in which active resorption and recalcification frequently coexist [5].

\section{Symptoms and clinical ENT Findings}

The main symptom of otosclerosis is a unilateral or bilateral progressive conductive hearing loss $(\mathrm{CHL})$ caused by foci on the oval window leading to stapes fixation with mechanical malfunction of the stiffened ring band [1, 3, 4]. Associated with this are typical results in the tuning fork tests (Rinne negative, Weber lateralized into the ear with stronger $\mathrm{CHL}$ ) and absent stapedius reflex in the diseased ear. The manubrium is easily moved (test with pneumatic ear magnifier), and the middle ear is well-ventilated (test with tympanogram). In general, history of inflammation of the middle ear is absent.
Otoscopy often reveals a circumscribed reddening on the promontory (Schwartze's sign), caused by hypervascularized otosclerotic lesions [3].

Tinnitus is evident in the majority of cases [5]. Vestibular symptoms are less frequent and are described as undirected short-term vertigo $[3,5]$.

Likewise, combined hearing loss resulting from cochlear involvement or up to $10 \%$ purely sensorineural hearing loss (SNHL) in isolated capsular otosclerosis are also observed [6, 7]. However, isolated capsular sclerosis without stapes fixation has been found very rarely in temporal bone preparations [8]. A typical phenomenon is the Carhart depression, a drop in bone conduction threshold of $15 \mathrm{~dB}$ in the pure tone audiogram at $1.5-2 \mathrm{kHz}[3,6,9]$.

Various hypotheses explain the presence of SNHL in cases of otosclerosis. Histologically, it has been shown that involvement of the cochlear wall in active otosclerotic foci was associated with collagen deposits in the spiral ligament (hyalinization) and atrophy of the adjacent stria vascularis [10-14]; SNHL can be explained by both changes. Other hypotheses assume damage to hair cells by cytotoxic enzymes, inflammatory cytokine mediators, oxidative stress and reactive oxygen species. It is possible that these molecules enter the endolymph, impair hair cell function and cause SNHL $[4,15]$. This hypothesis is supported by the detection of antioxidants in the serum of otosclerosis patients [16].

The symptoms and examination findings are not clearly pathognomonic. Clinical differential diagnoses include postinflammatory ossicular fixation (tympanosclerosis) or ossicular arrosion, traumatic ossicular dislocation, congenital cholesteatoma, middle ear malformations, Paget's disease, brittle bone disease (the latter two are very rare), pseudo $\mathrm{CHL}$ in dehiscence syndrome of the superior semicircular canal or in a mass in the inner ear, and apparent $\mathrm{CHL}$ in cases of insufficient masking in pure tone audiometry (detailed overview in [3]).

\section{Therapy}

To date there is no causal therapy for otosclerosis. Therapy options range from audiological follow-ups, conventional hearing aids, standard surgical therapy in the form of stapedoplasty to implantable hearing aids and cochlear implants [17].

In stapedoplasty, the stapes superstructure is removed, the stapes footplate is perforated (stapedotomy) and a prosthesis is inserted into this perforation, which is attached to the long process of the incus by a loop or clip [17]. Although hearing improvement can be expected in about $90 \%$ of operations [18, 19], and existing tinnitus is reduced after the operation [20], an approximately $1 \%$ risk of deafness must be taken into account $[18,19]$.

Drug therapy approaches may consist of the use of 3 rd generation bisphosphonates to prevent the progression of otosclerosis [21]. This, however, is not considered standard therapy. Active middle ear implants may be indicated in special cases, especially for moderate to profound hearing loss. Advanced otosclerosis with profound hearing loss bordering on deafness is an indication for a cochlear implant [3, 22, 23]. 


\section{Imaging Diagnostics}

\section{Current status}

Although the detection of otosclerosis-related lesions has already been achieved by polytomographic examinations [24, 25], and today even very small lesions can be depicted much more precisely by modern X-ray cross-sectional imaging [26-29], patients with a typical clinical otosclerosis constellation are often treated surgically without imaging. In the case of a combined or sensorineural hearing loss, a request for imaging is often made under the indication "unexplained hearing loss". False negative findings regarding otosclerosis may result if MRI is performed as the first or sole procedure for this issue. The imaging diagnosis of otosclerosis requires a cross-sectional X-ray [26-29], which can also reliably detect other middle ear pathologies causing unexplained hearing loss [26-29]. After a retrospective analysis of 259 CT scans performed on patients with clinically suspected otosclerosis, Dudau et al. [29] conclude that CT is a valuable aid in the management of otosclerosis patients. They determined a positive predictive value of $100 \%$ for CT for the diagnosis otosclerosis, a relevant alternative diagnosis in $33 \%$ of the cases and an influence of CT findings in the indication for stapedoplasty in $45 \%$ of the cases. In this study, image analysis was performed by radiologists experienced in temporal bone reading. The CT examination technology was optimal. In the authors' point of view, very subtle foci in the cochlear cleft are often overlooked in routine diagnostics, not least due to a suboptimal examination technique.

Hearing success can be proved immediately after stapes surgery. If employed, a postoperative documentation of the prosthesis by imaging is not performed in Germany. If a progressive decline of inner ear function occurs during the hospitalization phase, revision is frequent regardless of the outcome of imaging, if it is performed at all [30, 31]. In the event of a later recurrence of hearing loss or vestibular symptoms, imaging can disclose the cause in a high percentage of cases, thus supporting patient counseling and indication for re-operation [30, 32-34], where there is a higher risk of deafness than in the initial operation.

\section{Examination technology principles}

$\mathrm{CT}$, Cone Beam CT (CB-CT) and $3 \mathrm{D}$ rotational angiography are suitable for the detection of typical otosclerosis changes and postoperative complications. Currently, CT is regarded as the method of choice, as it is the only method that is widely available or can be used for otosclerosis diagnostics with respect to capacity. Due to the very small temporal bone structures, it is important to achieve optimal spatial resolution in all 3 procedures. Highquality axial and coronary multiplanar reconstructions (MPR) with a slice thickness of $0.3-0.6 \mathrm{~mm}$ should be created from a thin-layer isotropic axial data set; for CT, the spiral technique with the narrowest possible collimation should be selected [35]. The region of the oval window including the stapes plays a special role in pre- and postoperative imaging of otosclerosis patients. It can best be assessed by means of paraxial MPR [36], prepared with high magnification parallel to the longitudinal axis of the stapes by planning the sectional position on the coronal images ( $\vee$ Fig. 1). Due to spatial resolution and radiation hygiene, it is ad- visable to examine both temporal bones separately in CB-CT [37] and to blend exactly on temporal bone borders in $3 \mathrm{D}$ rotational angiography.

\section{Signs of otosclerosis on X-ray cross-sectional imaging}

Depending on the localization of the bone remodeling foci, a distinction can be made between fenestral and retrofenestral forms, whereby retrofenestral otosclerosis rarely occurs in isolation without fenestral involvement and is also assumed to be a continuation of the fenestral form [26, 38]. Of the histologically described stages, the otospongiotic phase is characterized by areas of reduced bone density (demineralized zones) and is the easiest to detect. In the otosclerotic stage and when remodeling processes are suspended, the foci are again more dense and more difficult to differentiate from normal surrounding bone. A concomitance of otospongiotic and sclerotic components is also frequently observed on imaging. Determination of density values in the CT analysis of otosclerosis lesions [39] has not become generally applied.

In fenestral otosclerosis the bone remodeling foci are located along the medial tympanic cavity wall. They are most commonly found in the fissula ante fenestram ( $\triangleright$ Fig. 2), a gap between the middle and inner ear located in front of the oval window and filled with fibrocartilaginous tissue in the embryonic period. Less frequent are plaques on the promontory, the round window ( $\triangleright$ Fig. 3) and the tympanic facial canal.

As the disease progresses, the entire footplate may be affected, which is sometimes very thickened after many years ( $\vee$ Fig. 2d). Familiarity with a thickened stapes footplate is helpful for stapedoplasty. During the recalcification phase, bony protrusions into the vestibule can occur ( $\vee$ Fig. $3 c$ ), which then constrict it. The windows, very rarely also the stapes, can also be completely ossified ( $\triangleright$ Fig. 3b, c). If a Cl should be inserted, a bony closed round window provides an obstacle to the insertion of the electrode array which must be removed or bypassed.

A little-known phenomenon is incudomalleolar separation as a result of otosclerosis ( $\triangleright \mathbf{F i g . 3 d}$ ) [26]. Due to the close positional relationship, plaques on the promontory often contact the basal turn of the cochlea, so that strictly speaking a mixed fenestral-retrofenestral form is thus present ( $\bullet$ Fig. $3 a, d$ ).

Retrofenestral involvement ( $\vee$ Fig. 4 ) occurs much more frequently due to the progression of fenestral otosclerosis with encroachment on the bone surrounding the membranous labyrinth than as an isolated manifestation ( $\triangleright$ Fig. 5). Depending on the stage of the disease, more or less dense, spotty or bandshaped plaques are found in the os petrosum. The cochlea may have a double-ring appearance (Valvassori sign) ( $\triangleright$ Fig. 4a). The otosclerotic lesions can reach all structures of the membranous labyrinth (cochlea, vestibule, semicircular canals, endo- and perilymphatic duct), the facial or internal auditory canal, but they can also lie isolated in the bone.

Despite the current high level of X-ray cross-sectional imaging technology, false negative findings in the sclerotic stage of fenestral otosclerosis cannot be completely excluded if there are no contour irregularities [40]. 

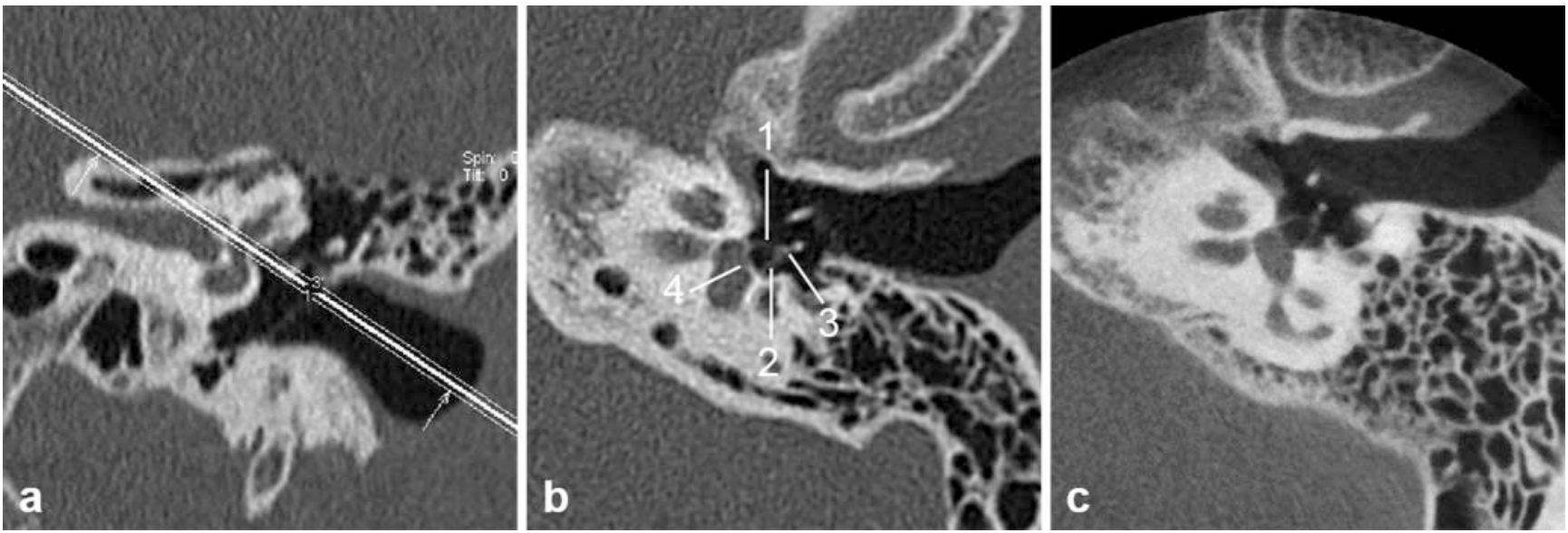

- Fig. 1 Normal anatomy of the oval window region. a Slice placement on the coronal CT image. b Paraxial CT image. c Paraxial CB-CT image. All components of the stapes well-depicted: Anterior (1), posterior crus (2) and head (3), called stapes superstructure, as well as the wafer-thin foot plate (4) in the oval window.
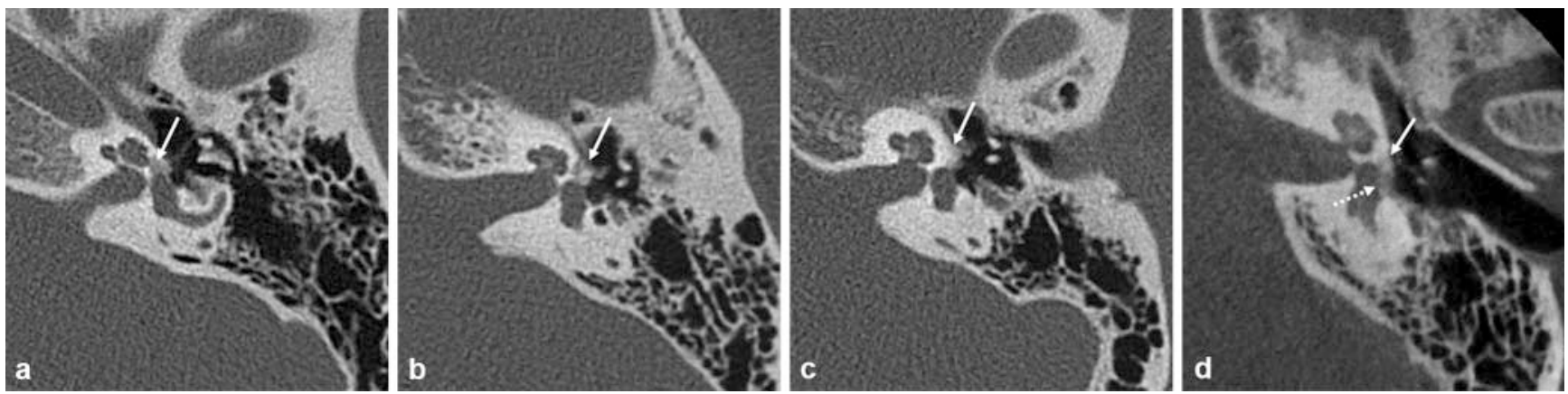

- Fig. 2 Fenestral otosclerosis with plaque in the fisslua ante fenestram (arrows). Good detectability in the otospongiotic a or mixed otospongiotic-otosclerotic phase $\mathbf{b}$. More difficult detection in the otosclerotic phase $\mathbf{c}, \mathbf{d}$. In $\mathbf{d}$ inclusion of the stapes footplate, which is greatly thickened (dotted arrow) - the stapes superstructure is missing after removal of the stapes prosthesis. a-c Axial CT, $\mathbf{d}$ paraxial CB-CT.
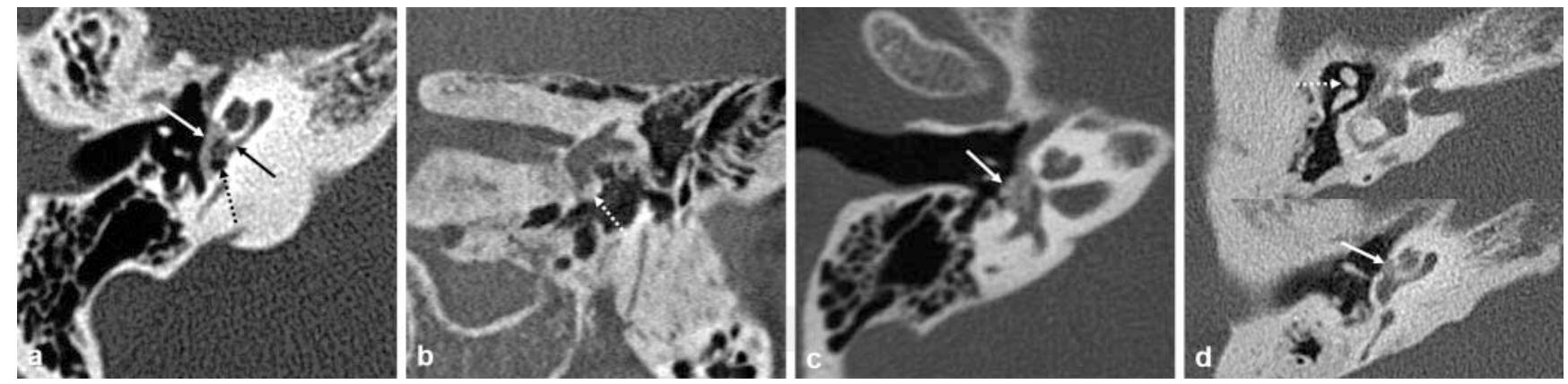

- Fig. 3 Fenestral otosclerosis. a Plaque on the promontory (white arrow), contacting the basal turn of the cochlea (black arrow) and spreading to the round window (dotted arrow). b Closure of the round window by an otosclerotic plaque (arrow) c Large otosclerotic plaque (arrow) with protrusions into and constriction of the vestibule and closure of the oval window. $\mathbf{d}$ Incudomalleolar separation (dotted arrow) as a result of otosclerosis - plaque on the promontory (arrow) with contact to the basal cochlear turn on a more caudal slice. a, $\mathbf{d}$ Axial CT, b Coronal CB-CT, $\mathbf{c}$ Paraxial CT.

In addition to the classification into fenestral and retrofenstral otosclerosis, various grading systems have been proposed in imaging studies depending on focal location, density and extent [41-43], none of which has been generally accepted to date.

\section{Signs of otosclerosis on the MRI image}

During the active phase, the otosclerotic foci accumulate contrast agent $[44,45]$ ( $\bullet$ Fig. 6 ), which is only noticeable on thin-sliced $(\leq 2 \mathrm{~mm})$ contrast-supported T1-weighted or FLAIR sequences. The foci are even more difficult to identify and only partially visi- 

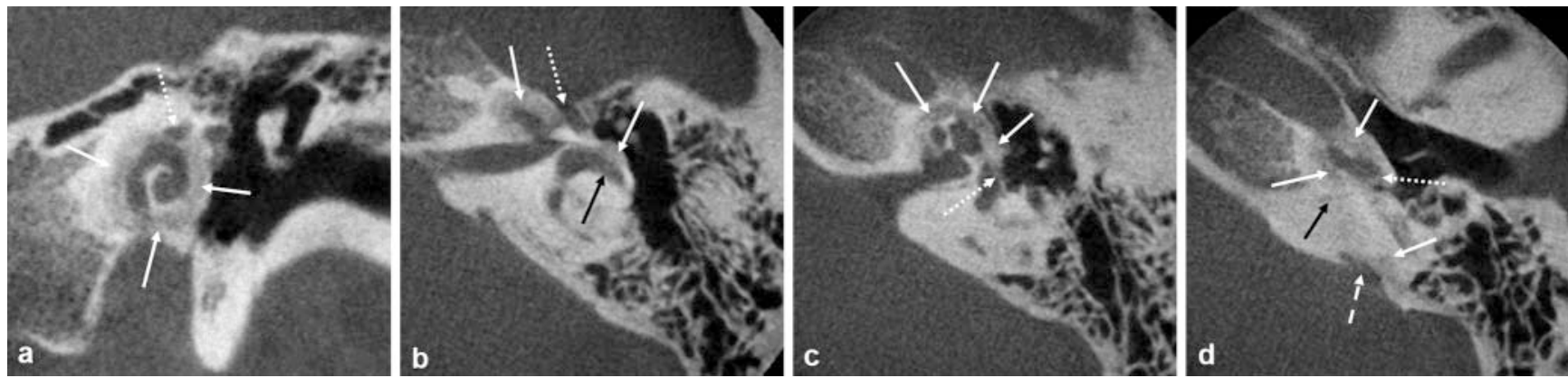

- Fig. 4 Mixed fenestral-retrofenestral otosclerosis with patchy and band-shaped bone remodeling zones (white arrows) in the bony labyrinth and along the medial tympanic cavity wall. a Double ring sign around the cochlea. a, b There is contact with the facial canal (dotted arrows) and anterior semicircular canal (black arrow). c Inclusion of the stapes footplate (dotted arrow). $\mathbf{d}$ Closure of the round window (dotted arrow), contact with the cochlear aqueduct (black arrow; includes perilymphatic duct) and vestibular aqueduct (dotted arrow; includes endolymphatic duct). a Coronal CB-CT, b-d Axial CB-CT.

ble as intermediate foci in the bony labyrinth on native T1-w sequences. If the findings are recognized, an X-ray cross-sectional image procedure should be performed to confirm the diagnosis. If the contrast enhancement is low or if the plaques are very small, in the experience of the authors, a false negative result is usually obtained in routine diagnostics. In the sclerotic stage, the diagnosis cannot be made be MRI.

\section{Differential diagnoses on imaging}

Radiology-based differential diagnoses primarily concern other osteodystrophies, which, however, are not isolated diseases of the temporal bone, but which can also affect it. Due to similar bone remodeling processes, otosclerosis is also known as isolated Paget's disease; image morphology is correspondingly similar ( $\triangleright$ Fig. 7a). No differentiation to retrofenestral otosclerosis can be made if only a cross-sectional X-ray examination of the temporal bone is available, and the onset of the disease or the age of manifestation, which in the case of Paget's disease is beyond the age of 40, is unknown. Involvement of the temporal bone in brittle bone disease is a rarity. Here the images likewise resemble those of retrofenestral otosclerosis [46]. However, it is unlikely that the diagnosis is not known at the time of imaging because patients exhibit typical clinical findings. Other bone remodeling diseases such as osteopetrosis and fibrous dysplasia are not considered as differential diagnoses due to their different appearance on X-Ray cross-sectional imaging.

Relevant differential imaging diagnoses are globuli ossei ( $\triangleright$ Fig. 7b), norm variants that the authors have so far only observed in younger children. These are remnants of embryonic cartilage, which, when located in the fissula ante fenestram fissula, are also referred to as the cochlear cleft [47]. They apparently ossify later ( $\vee$ Fig. 7c), and are seen between $32-40 \%$ in the pediatric population under 10 years of age $[47,48]$.

Congenital stapes fixation cannot be differentiated from fenestral otosclerosis on the basis of clinical findings and formerly could not be detected by CT. Advances in X-ray cross-sectional imaging have increasingly made it possible to visualize a thickened stapes base plate, sometimes also an ossified stapes superstructure, as an imaging morphological correlate when making paraxial recon-

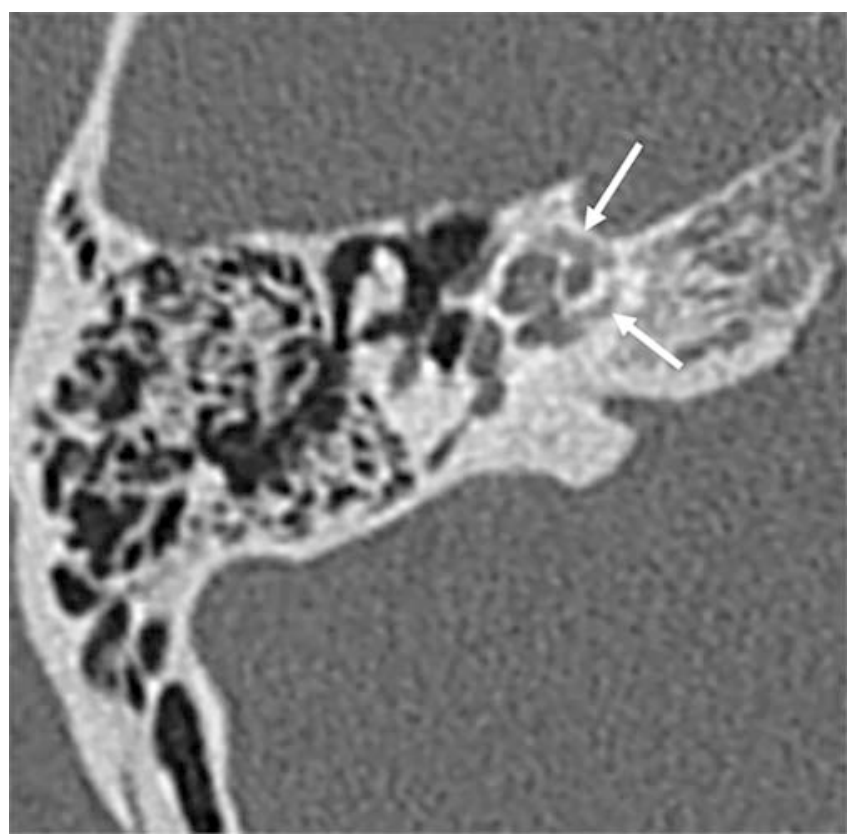

- Fig. 5 Isolated retrofenestral otosclerosis (capsular sclerosis) with band-shaped pericochlear density reduction (arrows). Asymptomatic incidental finding on imaging due to a contralateral cholesteatoma. Axial CT.

structions ( $\triangleright$ Fig. 7d). It is important that otosclerosis-typical foci with reduced density are absent.

Diseases that cause osteolysis, hydroptic ear disease and malformations are characterized by a different image morphology and therefore they are not a radiological differential diagnosis. A recent study has been shown that endolymphatic hydrops is common in advanced otosclerosis [49].

\section{Imaging after stapedoplasty}

Prostheses used today are usually made of titanium and have significantly fewer metal extinction artifacts than previously-used gold prostheses. Simplified, stapes prostheses consist of a piston and a loop or clip [17]. The different types differ mainly in the loop 

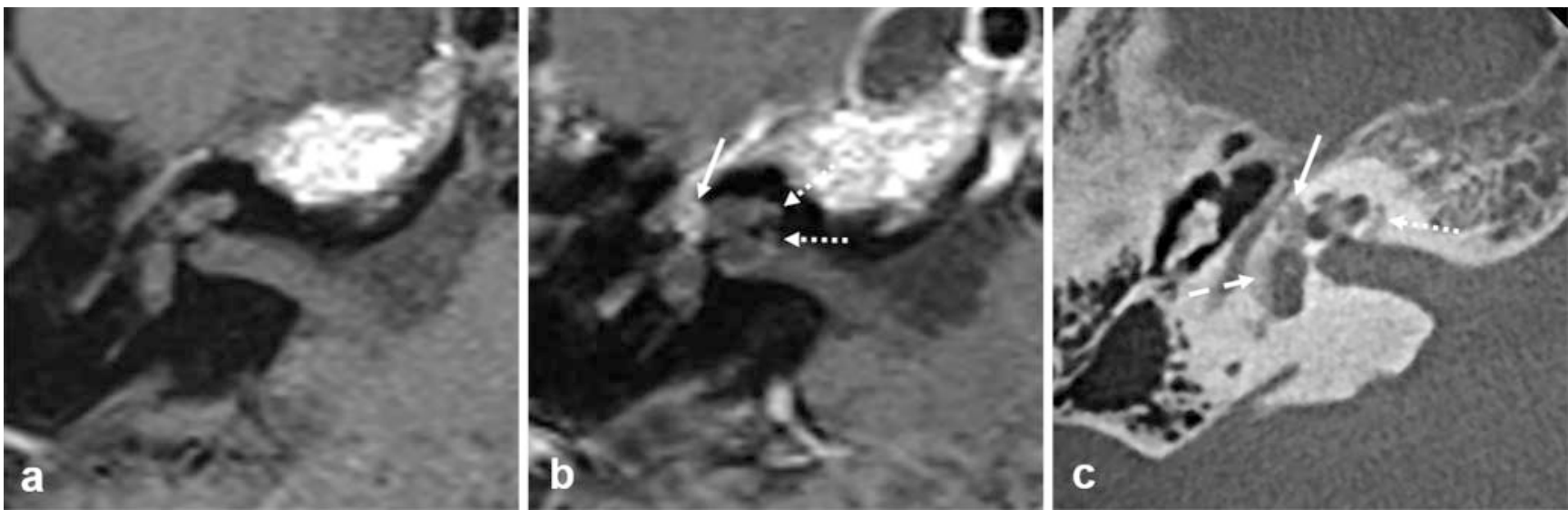

- Fig. 6 Comparison of MRI and CB-CT in otosclerosis. a, b On MRI, a lesion (arrow) located laterally on the cochlea shows significant enhancement, another medially located (dotted arrows) show very little enhancement, and a third one located on the vestibule (dotted arrow in c) does not show accumulated contrast. $\mathbf{c}$ On the basis of the CB-CT, the diagnosis can be clearly established. The foci demonstrate different densities. a Axial T1-weighting, b Axial CM T1-weighting, c Axial CB-CT.
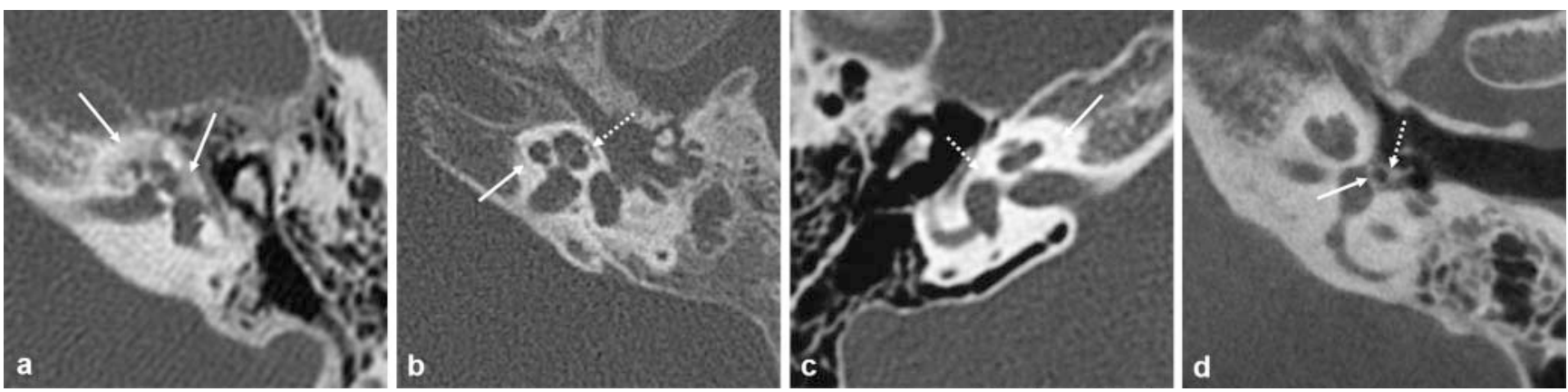

- Fig. 7 Radiological differential diagnosis to otosclerosis. a Retrofenestral bone remodeling areas (arrows) in a 64-year-old with known Paget's disease. b Globuli ossei (arrow) and 'cochlear cleft' (dotted arrow) in a 2-year-old. c In an 11-year-old, these changes (arrow, dotted arrow) can only be vaguely seen. $\mathbf{d}$ A thickened stapes footplate (arrow) and an ossified stapes superstructure (dotted arrow) without other foci indicate congenital stapes fixation. a-c Axial CT, d Paraxial CB-CT.

design, which cannot be differentiated on imaging. From the radiological point of view, the main task is to assess the position of the prosthesis on the basis of cross-sectional X-ray imaging. For an exact assessment, axis-aligned reconstructions are necessary, sometimes thin-sliced MIPs can be helpful.

When properly positioned, the stapes prosthesis is located in the posterior third of the oval window and does not protrude significantly beyond the window plane in the direction of the vestibule ( $\mathbf{F i g . 8 a , ~ b ) ~ [ 3 0 - 3 4 ] . ~ I n ~ t h e ~ m i d d l e ~ e a r ~ i t ~ i s ~ u s u a l l y ~}$ attached to the long process of the incus.

Prosthesis dislocation is the most frequent complication after stapedoplasty, which is usually accompanied by an acute functional disorder. If there is dislocation into the tympanic cavity ( $\mathbf{F i g . ~} \mathbf{8 c}$, d), then a more or less large gap arises between the end of the prosthesis and the stapes footplate, which prevents sound transmission to the inner ear fluid, and the patient suffers from renewed hearing loss. In dislocations into the vestibule ( $\triangleright$ Fig. 9) usually vertigo is to the fore. In some cases, triggering factors for prosthesis dislocation can also be found, such as a loosening of the anchorage on the long process of the incus ( $\nabla$ Fig. $9 c, d$ ), a prosthesis fracture ( $\triangleright$ Fig. 10a, b) or a necrosis of the incus as a late complication ( $\triangleright$ Fig. 10c); in the latter case, there is a wafer-thin long incus process. Scarring ( $\triangleright$ Fig. 10d) can be assumed if the prosthesis is surrounded by flat or strand-like opacifications that draw towards the eardrum, which appears retracted.

Rare complications include perilymph fistula and granulations. Indirect signs of a perilymph fistula include air in the vestibule (this sign is useless shortly after stapedotomy, as air may have penetrated intraoperatively and has not yet been resorbed [31]) and/or a fluid level in the tympanic sinus.

If none of the described changes are present on X-Ray crosssectional images in suspected complications, it is recommended to perform an MRI of the temporal bone, since granulation can only be classified reliably in this way [30]. They are characterized by strong contrast enhancment. In extremely rare cases, they can extend intracranially via the inner ear/inner auditory canal. 

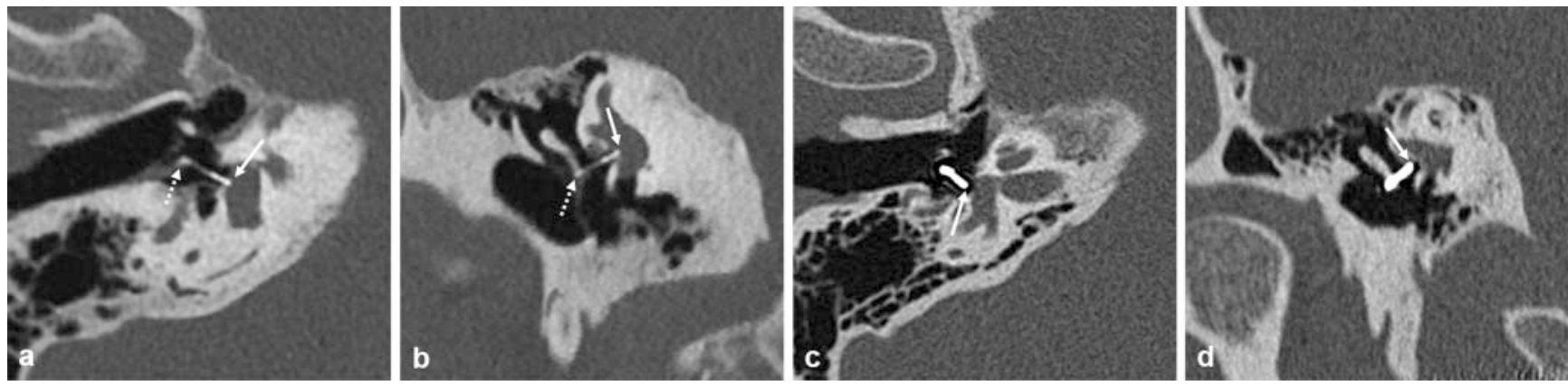

- Fig. 8 Condition post-stapedoplasty. a, b Proper prosthesis position: Seat in the posterior third, the piston does not protrude significantly beyond the oval window plane (arrows), the loop is attached to the long incus process (dotted arrows). c, d Minor dislocation into the tympanic cavity there is a gap between the end of the piston (arrows) and the stapes footplate in the oval window. On the axial image, delicate metal artifacts surround the prosthesis. a, $\mathbf{c}$ Paraxial CT; b, d Coronal CT.
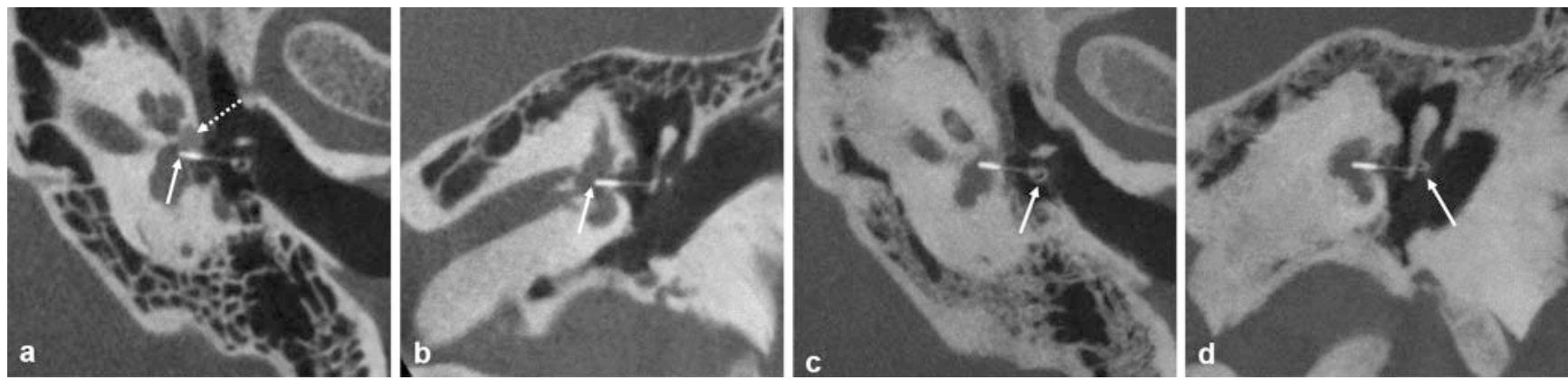

- Fig. 9 Condition post-stapedoplasty Prosthesis dislocation into the vestibule. a, b Decentralized position and too deep dipping of the piston into the vestibule (arrows). Otospongiotic plaque in the fissula ante fenestram (dotted arrow). c, $\mathbf{d}$ Loosening of the prosthesis anchorage at the long incus process (arrows). a Paraxial CB-CT, b Coronal CB-CT, c Paraxial CB-CT MIP, d Coronal CB-CT MIP.
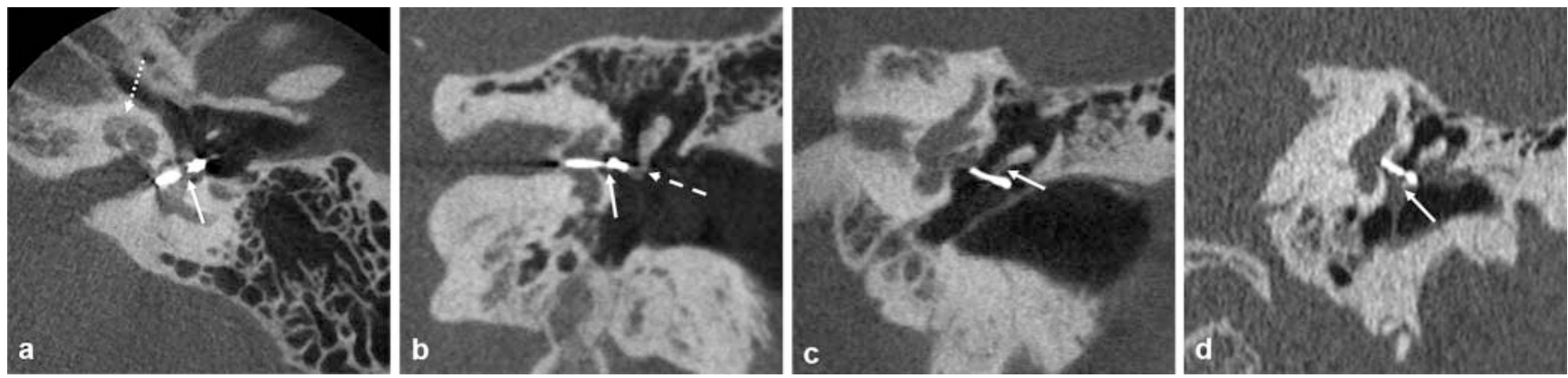

- Fig. 10 Condition post-stapedoplasty. a, b Deep dislocation into the vestibule, prosthesis fracture (arrows); the loop is no longer attached to the long anvil leg (dotted arrow). Otospongiotic plaque on the cochlea (dotted arrow). c Distinct prosthesis dislocation in the tympanic cavity in due to anvil necrosis (arrow). d Proper prosthesis position. The prosthesis and the retracted ear drum are connected by focal opacification (arrow), resulting from scar tissue. a Paraxial CB-CT, b, c Coronal CB-CT, $\mathbf{d}$ Coronal CT.

\section{Summary}

Unlike the ENT physician, the radiologist rarely encounters otosclerosis. The much more common fenestral form is associated with a typical clinical constellation where imaging is not considered necessary to confirm the diagnosis. In this form the image morphological changes can be very discreet. On X-ray cross- sectional imaging technique and targeted search are necessary for their detection. The situation is different in mixed forms and the very rare isolated retrofenstral otosclerosis. Here the radiologist plays a crucial role in establishing the correct diagnosis. If complications after stapedoplasty are suspected, the radiologist can provide information regarding the cause and can support the indication for repeated surgery. 


\section{Conflict of Interest}

The authors declare that they have no conflict of interest.

\section{References}

[1] Karosi T, Szekanecz Z, Sziklai I. Otosclerosis: an autoimmune disease? Autoimmun Rev 2009; 9: 95-101

[2] Declau F, Van Spaendonck M, Timmermans JP et al. Prevalence of otosclerosis in an unselected series of temporal bones. Otol Neurotol 2001; 22: $596-602$

[3] Metasch ML, Plontke SK, Zirkler J et al. Diagnostik and operative Therapie der Otosklerose. Teil1: Grundlagen, Diagnostik und Differentialdiagnostik. Laryngo-Rhino-Otol 2018; 97: 563-578

[4] Rudic M, Keogh I, Wagner R et al. The pathophysiology of otosclerosis: review of current research. Hear Res 2015; 330: 51-56

[5] Strutz J. Otosklerose. In: Strutz J, Mann W, Arndt O, (eds) Praxis der HNOHeilkunde, Kopf- und Halschirurgie. Stuttgart: Thieme; 2010: 282-284

[6] Foster MF, Backous DD. Clinical evaluation of the patient with otosclerosis. Otolaryngol Clin N Am 2018; 51: 319-326

[7] Browning GG, Gatehouse S. Sensorineural hearing loss in stapedial otosclerosis. Ann Otol Rhinol Laryngol 1984; 93: 13-16

[8] Schuknecht HF. Cochlear otosclerosis. An intractable absurdity. J Laryngol Otol 1983; 8: 81-83

[9] Carhart R. Clinical application of bone conduction audiometry. Archives of Otolaryngology 1950; 51: 798-808

[10] Kwok OT, Nadol JB Jr. Correlation of otosclerotic foci and degenerative changes in the organ of Corti and spiral ganglion. Am J Otolaryngo 1989; 10: 1-12

[11] Parahy C, Linthicum FH Jr. Otosclerosis: relationship of spiral ligament hyalinization to sensorineural hearing loss. Laryngoscope 1983; 93: 717-720

[12] Lindsay JR, Beal DD. Sensorineural deafness in otosclerosis. Observations on histopathology. Ann Otol Rhinol Laryngol 1966; 75: 436-457

[13] Elonka DR, Applebaum EL. Otosclerotic involvement of the cochlea: a histologic and audiologic study. Otolaryngol Head Neck Surg 1981; 89: 343-351

[14] Doherty JK, Linthicum FH Jr. Spiral ligament and stria vascularis changes in cochlear otosclerosis: effect on hearing level. Otol Neurotol 2004; 25: 457-464

[15] Babcock TA, Liu XZ. Otosclerosis. From genetics to molecular biology. Otolaryngol Clin N Am 2018; 51: 305-318

[16] Baysal E, Gulsen S, Aytac I et al. Oxidative stress in otosclerosis. Redox Rep Commun Free Radic Res 2017; 22: 235-239

[17] Plontke SK, Metasch ML, Zirkler J et al. Diagnostik und operative Therapie der Otosklerose. Teil II: Operative Therapie. Laryngorhinootologie 2018: 97: 717-734

[18] Antonelli P. Prevention and management of complications in otosclerosis surgery. Otolaryngol Clin North Am 2018; 51: 453-462

[19] Cheng HCS, Agrawal SK, Parnes LS. Stapedectomy versus stapedotomy. Otolaryngol Clin North Am 2018; 51: 375-392

[20] Ayache D, Earally F, Elbaz P. Characteristics and Postoperative Course of Tinnitus in Otosclerosis. Otol Neurotol 2003; 24: 48

[21] de Penido NO, de Vicente AO. Medical Management of Otosclerosis. Otolaryngol Clin North Am 2018; 51: 441-452

[22] Rahne T, Plontke SK. Apparative Therapie bei kombiniertem Hörverlust. HNO 2016; 64: 91-100
[23] Beutner D, Delb W, Frenzel H et al. Leitlinie „Implantierbare Hörgeräte“ Kurzversion: S2k-Leitlinie der Arbeitsgemeinschaft Deutschsprachiger Audiologen, Neurootologen und Otologen (ADANO), der Deutschen Gesellschaft für Hals-Nasen-Ohren-Heilkunde, Kopf- und Hals-Chirurgie (DGHNO) unter Mitarbeit der Deutschen Gesellschaft für Audiologie (DGA), der Deutschen Gesellschaft für Phoniatrie und Pädaudiologie (DGPP) und von Patientenvertretern. HNO 2018; 66: 654-659

[24] Freeman J. Progressive sensorineural hearing loss and cochlear otosclerosis: A prospective study. Laryngoscope 1979; 89: 1487-1521

[25] Forqueer BD, Seehy JL. Cochlear otosclerosis: a review of audiometric findings in 150 cases. Am J Otol 1987; 8: 1-4

[26] Purohit B, Hermans R, Op de Beeck K. Imaging in otosclerosis: A pictorial review. Insights Imaging 2014; 5: 245-252

[27] Kösling S, Hoffmann K. Otosklerose. In: Kösling S, Bootz F, (eds). Bildgebung HNO-Heilkunde. Berlin, Heidelberg: Springer; 2015: 122-125

[28] Lemmerling M. Otosclerosis. In: Lemmerling M, De Foer B, (eds). Temporal Bone Imaging. Berlin, Heidelberg: Springer; 2015: 89-96

[29] Dudau C, Salim F, jiang D et al. Diagnostic efficacy and therapeutic impact of computed tomography in the evaluation of clinically suspected otosclerosis. Eur Radiol 2017: 27: 1195-1201

[30] Kösling S, Bootz F. CT and MRI after middle ear surgery. Europ J Radiol 2001; 40: 113-118

[31] Kösling S, Brandt S, Bloching M et al. Indikationen für die HR-CT nach erfolgter Stapedotomie in der frühen postoperativen Phase. Fortschr Röntgenstr 2004; 176: 1122-1126

[32] Woldag K, Kösling S, Meister EF et al. Diagnosis in the presence of persistent vertigo after stapes surgery. Laryngo-Rhino-Otologie 1995; 74: 403-407

[33] Kösling S, Woldag K, Meister EF et al. Stellenwert der Computertomografie bei persistierenden Gleichgewichtsstörungen nach dem Einsatz von Stapesplastiken. Fortschr Röntgenstr 1995; 162: 3-6

[34] Kösling S, Woldag K, Meister EF et al. Value of computed tomography in patients with persistent vertigo after stapes surgery. Invest Radiol 1995; 30: 712-715

[35] Arbeitsgemeinschaft Kopf-Hals-Diagnostik der Deutschen Röntgengesellschaft. CT- und MRT-Protokolle. www.drg.de

[36] Henrot $P$, lochum $S$, Batch $T$ et al. Current multiplanar imaging of the stapes. Am J Neuroradiol 2005; 26: 2128-2133

[37] Knörgen M, Brandt S, Kösling S. Qualitätsvergleich digitaler 3D-fähiger Röntgenanlagen bei HNO-Fragestellungen am Schläfenbein und den Nasennebenhöhlen. Fortschr Röntgenstr 2012; 184: 1153-1160

[38] Valvassori GE. Imaging of otosclerosis. Otolaryngol Clin North Am 1993 26: 359-371

[39] Kawase S, Naganawa S, Sone M et al. Relationship between CT densitometry with a slice thickness of $0.5 \mathrm{~mm}$ and audiometry in otosclerosis. Eur Radiol 2006; 16: 1367-1373

[40] Naumann IC, Porcellini B, Fisch U. Otosclerosis: incidence of positive findings on high resolution computed tompography and their correlation to audiological test data. Ann Otol Rhinol Laryngol 2005; 114: 709-716

[41] Shin Y], Fraysse B, Deguine O et al. Sensorineural hearing loss and otosclerosis: a clinical and radiological survey of 437 cases. Acta Otolaryngol 2001; 121: 200-204

[42] Marshall AH, Fanning N, Symons S et al. Cochlear implantation in cochlear otosclerosis. Laryngoscope 2005; 115: 1728-1733

[43] Lee TC, Aviv RI, Chen JM et al. CT grading of otosclerosis. Am J Neuroradiol 2009; 30: 1435-1439 
[44] Stimmer H, Arnold W, Schwaiger M et al. Magnetic resonance imaging and high-resolution computed tomography in the otospongiotic phase of otosclerosis. J Otorhinolaryngol Relat Spec 2002; 64: 451-453

[45] Goh JPN, Chan LL, Tan TY. MRI of cochlear otosclerosis. Br J Radiol 2002; 75: 502-505

[46] Ziyeh S, Berger R, Reisner K. MRI-visible pericochlear lesions in osteogenesis imperfect type I. Europ Radiol 2000; 10: 1675-1677

[47] Chadwell JB, Halsted MJ, Choo DI et al. The cochlear cleft. Am J Neuroradiol 2004; 25: 21-24
[48] Pekkola J, Pitkäranta A, Jappel A et al. Localized pericochlear hypoattenuating foci at temporal-bone thin-section $\mathrm{CT}$ in pediatric patients: nonpathologic differential diagnostic entity. Radiology 2004; 230 : $88-92$

[49] Wang F, Yoshida T, Sugimoto S et al. Clinical features of ears with otosclerosis and endolymphatic hydrops. Otol Neurotol 2019; 40: 441-445 